\title{
EL “ABC” DE LA PREDICACIÓN EVANGÉLICA
}

Gabriel Vela Vásquez, Mg.

Facultad de Teología

Universidad Peruana Unión

gabrielvela@teologia.edu.pe

Fecha de recepción: Octubre 2014. Fecha de aceptación y versión final: Diciembre 2014.

Este artículo muestra los componentes básicos que debe poseer un buen sermón. Este debe ser: (A) Bíblico (B) Cristocéntrico, conciso, corto; y (C) aplicable a la vida del creyente. Una buena predicación está basada en una buena teología, en una perspectiva explícitamente encomendada por el cielo, para ser compartida entre los seres humanos, con el sublime objetivo de brindarles direccionamiento y consuelo, pero por sobre todo, la Palabra debe ser expuesta. Ni la experiencia ni el conocimiento pueden predicar por la Palabra, sino que la misma Palabra determina toda experiencia, conocimiento y doctrina. El acto de predicar es el acto de presentar la Palabra viva que da vida.

Palabras clave: Predicación, sermón, mensaje cristocéntrico, homilética 


\section{THE 'ABC' OF EVANGELISTIC PREACHING}

Abstract

This article shows the basic components that a good sermon must possess. These should be: (A) Christ-centered, (B) Biblical and concise; and (C) applicable to the believer's life. Good preaching is based on sound theology, in a perspective explicitly entrusted by heaven, to be shared between humans, with the sublime goal of providing comfort and guidance. But above all, the Word must be exposed. The act of preaching is the act of presenting the live Word, which conveys life.

Keywords: Preaching, sermonm Christ-centered message, homiletic 


\section{Introducción}

Para el apóstol Pablo, la predicación es el medio seleccionado por Dios para salvar al mundo pecador; el predicador no tiene poder para perdonar pecados, pero son los llamados a proclamar que Cristo perdona los pecados (1 Co 1:17). Por lo tanto, la predicación para Pablo era un acto de obediencia (2 Ti 4:2). Charles Spurgeon, el gran predicador inglés dijo a sus alumnos: "Si Dios te hizo predicador, no 10 te detengas en el camino para ser rey". "Cristo fundó una comunidad, una iglesia, cuya primera función fue predicar el evangelio".

Si la predicación va a contribuir con la adoración, el predicador debe tener una preparación completa del corazón y de la mente. La real calidad del sermón depende de un espíritu disciplinado, una mente

${ }^{1}$ Franklin M. Segler, Christian Worship (Nashville, TN: Broadman \& Holman Publishers, 1996), 115. despejada, un conocimiento de la gente y una vital experiencia del poder salvador de Dios en la vida del predicador. Una buena predicación está basada en una buena teología, y una mala predicación no cumple el ideal divino; por tanto, en este estudio analizaremos el "ABC" de la predicación: (A) El sermón debe ser bíblico, (B) Cristocéntrico, conciso y corto, y (C) aplicable a la vida del oyente. El imperativo permanece y dice: ¡Predica la Palabra!, prepara y predica con propiedad la Palabra de Dios.

\section{A: El sermón debe ser bíblico}

El ministerio de Jesús provee una guía que todo predicador debe seguir; él era un predicador laico, no era sacerdote, ni escriba, ni saduceo o fariseo, él era un hombre ordinario; no tenía credenciales como teólogo, pero su predicación era poderosa, desafiante y con autoridad. Los oyentes se sorprendían al oír las poderosas pala- 
bras de boca de un carpintero. La predicación de Jesús tenía autoridad porque hablaba la Palabra de Dios. Él predicó no lo que le gustaba escuchar a la gente sino lo que necesitaban escuchar, y lo que más necesitaban sus oyentes era escuchar la Palabra de Dios.

Todo sermón debe estar basado en la palabra de Dios; es decir, debe ser bíblico; si no es bíblico no debe ser predicado. Todo sermón debe estar basado en las Sagradas escrituras, Jesús predicó la Palabra de Dios porque la conocía. Él conocía el Antiguo Testamento, se preparó por muchos años antes de comenzar su ministerio público, escuchó la voz de Dios, la usó con inteligencia, practicó lo que predicaba, y estableció credibilidad entre sus creyentes. El predicador debe ser disciplinado, debe dedicar tiempo para la lectura de la Biblia, leer grandes libros sobre diferentes tópicos y de teología. Debe tener períodos habituales de oración y meditación y una sensibilidad de la presencia de Dios en su vida y en la vida de los demás. El predicador debe conocer la Biblia.

Hay sermones que parecen ser bíblicos, están llenos de material bíblico pero no son sermones, ¿por qué? Porque son meras repeticiones históricas y lecturas bíblicas. Los textos son explicados correctamente, pero la aplicación de los mismos a la vida de los oyentes es nula; la calidad real de un sermón bíblico se mide por la manera en que el texto bíblico se conecta a la vida del oyente y cuando el texto es relevante para la vida presente.

"Todo predicador debe conocer la Biblia, debe tomar la sabiduría divina y comunicarlo en el poder del espíritu a la comunidad de fe, en adición al conocimiento de la Biblia, los predicadores sabios leerán libros de teología, psicología, historia, arqueología bíblica y de ciencia; estas fuentes de conocimiento reforzarán el conocimiento del 
predicador y le serán de gran ayuda". ${ }^{2}$

\section{B: El sermón debe ser cristocéntrico, conciso y corto}

\section{El sermón debe ser cristocéntrico}

El predicador debe buscar un pretexto para hacer de Cristo su contexto. En cada sermón, el predicador debe buscar un pretexto para hablar de Jesús. En cada sermón, la persona

12 de Jesús tiene que aparecer; Jesús debe ser el sujeto principal, debe dársele un espacio para que aparezca. Los predicadores cristianos debería predicar como Cristo predicó y predicar lo que él predicó.

"El gran centro de atracción, Cristo Jesús, no debe ser dejado fuera del mensaje del tercer ángel... Cristo crucificado, Cristo resucitado, Cristo

${ }^{2}$ Raymond Bailey, Jesus the Preacher (Nashville, TN: Broadman Press, 1990), 30. ascendido al cielo, Cristo que va a volver, debe enternecer, alegrar y llenar de tal manera la mente del predicador, que sea capaz de presentar estas verdades a la gente con amor y profundo fervor". ${ }^{3}$

La real calidad del sermón depende de un espíritu disciplinado, del conocimiento de la Palabra, del conocimiento de la iglesia y de una vital experiencia del poder salvador de Dios.

Toda predicación debe ser un esfuerzo para captar y exaltar el nombre de Dios, lo que Dios ha hecho y hará por nosotros al darnos a Jesucristo como nuestro salvador.

El sermón debe ser corto

Thom y Joani Schultz presentan una encuesta respecto a la recepción de un sermón; ellos encontraron que: "Tan solo un $12 \%$ recuerda el mensaje del sermón, el $87 \%$ dice

${ }^{3}$ Elena G. de White, El evangelismo (Buenos Aires, Argentina: Casa Editora Sudamericana, 1978), 138, 139. 
que su mente divaga durante el sermón, el 35\% dice que los sermones que escuchan son demasiado largos, un $11 \%$ de las mujeres y un 5\% de los hombres ven los sermones como una fuente principal del conocimiento sobre Dios". ${ }^{4}$

¿Cuál es el real problema de la predicación? El problema radica en el medio: desconocen el medio que utilizan para exponer la Palabra de Dios, lo más importante es lo que el oyente ve: la apariencia del predicador, sus ademanes, sus movimientos, las ayudas visuales que utiliza. ${ }^{5}$

"Algunos de vuestros discursos largos tendrían mucho mejor efecto sobre la gente si se los dividiese en tres. La gente no puede digerir tanto, sus mentes ni aun lo pueden abarcar, y llegan a cansarse y confundirse al tener tanto material delante de

${ }^{4}$ Thom y Joani Schultz, Por qué nadie aprende mucho de nada en la Iglesia (Loveland, CO: Editorial Acción, 1995), 187. ellos en un solo discurso. Las dos terceras partes de los discursos tan largos se pierden, y el predicador se agota". ${ }^{6}$

Un sermón corto es un buen sermón. Un buen sermón debe variar entre 30 a 40 minutos de duración, lo ideal es predicar un sermón en 30 minutos. Tony Campolo dice que un sermón de 20 minutos es un "sermonete”. Si el sermón es bueno y corto será una buena predicación y el predicador será un ganador; si el sermón es corto y malo no será una buena predicación, solo será un discurso.

El sermón debe ser conciso

Las palabras reflejan el pensamiento y la acción definida y deben ser cuidadosa e intencionalmente escogidas para que comuniquen con toda efectividad el mensaje.

El predicador debe usar y escoger un lenguaje moderno, palabras y términos de fá-

${ }^{6}$ White, 133.

${ }^{5}$ Schultz, 191. 
cil comprensión y debe evitar el lenguaje estereotipado. Por otro lado, el tono debe ser vívido y vigoroso. El predicador debe predicar con un propósito específico.

Un sermón necesita unidad y una clara declaración de una idea central; esto provee una guía para el desarrollo armonioso del sermón desde el título hasta la conclusión. La idea central es lo que el sermón dice, ni más ni menos; la idea central es conocida como el tema, la proposición, la tesis, es el quid del asunto; es decir, el punto esencial. El predicador no debe divagar presentando otros temas, debe enfocarse en la tesis propuesta.

\section{El sermón debe ser aplica- ble a la vida del oyente}

En homilética, "aplicación" involucra la obra de conectar la importancia de la verdad declarada en el texto bíblico y el sermón con la situación y necesidad del oyente. La aplicación en el sermón apunta a la rela- ción que existe entre lo que se ha dicho y la vida del oyente; es un llamado de atención al ¿cómo?, al ¿qué?, y al ¿por qué? Es importante poner en práctica la verdad presentada por el predicador. ${ }^{7}$

La aplicación en el sermón debe ser enfocado en persuadir al oyente para aceptar y poner en práctica la verdad presentada. El predicador debe comunicar con claridad e inspiración el sermón a fin de que la aplicación se dé. El buen sermón debe ayudar a la audiencia a solucionar sus necesidades y sus problemas. El sermón tiene que ser de ayuda para la audiencia. $\mathrm{Si}$ el sermón no produce fe, no fue predicación. El sermón debe dar la receta correcta para solucionar los problemas y debe curar la enfermedad del oyente.

La prueba de un buen sermón es el efecto que tiene en los oyentes. La predicación depende de la respuesta y reacción de los

${ }^{7}$ Michael Duduit, Contemporary Preching (Nashville, TN: Broadman Press, 1992), 209. 
oyentes, ya que la congregación no es simplemente una audiencia que se mantiene pasiva mientras se produce la predicación; entre el predicador y los oyentes debe haber una real conexión. Los adoradores son la fuente del sermón, porque sus vidas y necesidades moldean y hacen al predicador. El primer propósito de la predicación es edificar a la iglesia y no glorificar al predicador. El predicador debe entender tanto el contexto original y contemporáneo del texto, a fin de que el mensaje pueda ser aplicado a las necesidades de la iglesia.

"Aplíquese en todo discurso la verdad al corazón, para que todo el que oiga entienda, y para que los hombres, las mujeres y los jóvenes revivan ante Dios". 8

\section{Conclusión}

La calidad de un buen sermón depende de varios factores: Un buen sermón debe ser

\footnotetext{
${ }^{8}$ White, 134.
}

bíblico, debe ser cristocéntrico; es decir, debe exaltar a Cristo; debe ser pertinente, actual, auténtico; debe tener una idea central a fin de que el oyente pueda con facilidad entender y seguir con atención la predicación; debe ayudar al oyente en su vida diaria, debe ayudarle a solucionar sus necesidades y sus problemas; en otras palabras, debe ser aplicable a su real situación; debe tener una idea clara y debe ser corto, no más de 40 minutos.

La predicación es arte y es ciencia, no es fácil llegar a ser un buen predicador; es muy difícil alcanzar la perfección en la predicación, por eso es que no hay buenos predicadores. La predicación es un don de Dios. No debemos desanimarnos. Debemos darle la debida importancia a la predicación, ya que ella es la tarea primordial de la iglesia; que otras áreas de la iglesia no ocupen su lugar preferencial. La Palabra de Dios debe ser predicada en todo tiempo, en todo lugar, con fe, paciencia e inteligencia. 


\section{Referencia}

Bailey, Raimond. Jesus the Preacher. Nashville, TN: Broadman Press, 1990.

Duit, Michel. Comtemporary Preacher. Nashville, TN: Broadman Press, 1992.

Segler, M. Franklin. Christian Worship. Nashville, TN: Broadmam \& Holman Publisher, 1996.
Shultz, Tom y Joani. Por qué nadie aprende mucho de nada en la Iglesia. Loveland CO: Editorial Acción, 1995.

White, Elena de. El Evangelismo. Buenos Aires: Casa Editora Sudamericana, 1978. 